\title{
Study of precipitation along a concentration gradient
}

\author{
C. G. Garay-Reyes ${ }^{1}$, I. Estrada-Guel ${ }^{1}$, J.L. Hernández-Rivera ${ }^{2}$, J. M. Mendoza-Duarte ${ }^{1}$, E. Cuadros- \\ Lugo $^{1}$, S. E. Hernandez-Martinez ${ }^{2}$, J .J Cruz-Rivera ${ }^{2}$ and R. Martínez-Sánchez ${ }^{1}$. \\ ${ }^{1 .}$ Centro de Investigación en Materiales Avanzados (CIMAV) Miguel de Cervantes No. 120, 31109 , \\ Chihuahua, Chih., México. \\ 2. Universidad Autónoma de San Luis Potosí, Instituto de Metalurgia, Sierra leona 550, Col. Lomas 2 \\ sección, 78210, S.L.P, México.
}

The present work is based on the microstructural characterization method proposed by T. Miyazaki [13], the so-called Macroscopic Composition Gradient (MCG) method. This technique allows the investigation of phase transformations in a single specimen and helps to evaluate the mechanical properties for different alloy compositions. It is based on the microstructural observation of a continuous concentration gradient, which can be generated by several methods, for instance, diffusion coupling, imperfect homogenization of coarse discontinuous precipitates, etc.

Buttons of $\mathrm{Ni}-11.5$ wt. \% $\mathrm{Ti}$ alloy and pure $\mathrm{Ni}$ were melted in an electric-arc furnace under an argon atmosphere using pure elements $(99.9 \%)$. An assembly consisting of the buttons was placed into an austenitic stainless steel holder with two screws, encapsulated into a quartz tube under an argon atmosphere and heat treated at $1200{ }^{\circ} \mathrm{C}$ for $28 \mathrm{~h}$ to promote the diffusion and generate the concentration gradient in the diffusion couple, subsequently, the diffusion couple was isothermally aged at 850, 750 and $650{ }^{\circ} \mathrm{C}$ for different times. Microstructural characterization was carried out by High Resolution Scanning Electron Microscopy (HR-SEM) using a JSM-7401F microscope with Energy Dispersive Spectroscope (EDS).

The diffusion process that occurs during annealing and aging treatments produces a characteristic microstructure in the diffusion couple, where the Kirkendall effect and a mixture of phases are evidenced. The Fig. 1a shows the microstructure at the interface of the $\mathrm{Ni}-13.75 \mathrm{Ti}($ at. \%)/Ni diffusion couple after annealing at $1200{ }^{\circ} \mathrm{C}$. The variation of $\mathrm{Ti}$ concentration as a function of distance is also shown in this figure evidencing the concentration gradient at the diffusion couple interface. A region of about $140 \mu \mathrm{m}$ that goes from the interface to the Ti-rich side, delimited by the solvus line, exhibits the presence of voids, which are formed due to the different diffusion rates of the diffusing elements. As reported elsewhere [4], the Ni diffusion rate is higher than that of Ti. Figs. $1 \mathrm{~b}$ and 1c, show the solvus line and the precipitation boundary of the $\gamma^{\prime}$ phase in samples thermal aged at $850{ }^{\circ} \mathrm{C}$. The phases observed in these figures with cuboidal-shaped morphology correspond to $\gamma^{\prime}$ phase and those with plateshaped morphology to $\mathrm{Ni}_{3} \mathrm{Ti}$ precipitates $\left(\eta-\mathrm{D}_{24}\right)$. The solvus and the precipitation boundary of the $\gamma^{\prime}$ phase determined experimentally by EDS were found at 9.16 and $9.92 \mathrm{Ti}$ (at. \%), respectively. These values are close to the corresponding values in the Ni-Ti phase diagram [5].

The variation in Vickers hardness (HVN) as function of aging time in Ni-rich Ni-Ti alloys with different Ti concentration is shown in Fig. 2. The maximum hardness observed (under all temperatures) is related with the presence of $\gamma^{\prime}$ precipitates. In addition, it is observed that as aging temperature decreases, the $f v$ of precipitates and the HVN increase, but at concentrations less 6 at. \% Ti there is not precipitation hardening at 3 aging temperatures studied. 


\section{References}

[1] T. Miyazaki, T. Koyama, S. Kobayashi, Metall Mater Trans 27A (1996). p. 949-954.

[2] T. Miyazaki, S. Kobayashi, T. Koyama, Metall Mater Trans 30A (1999), p. 2783-2789.

[3] T. Miyazaki, Prog Mater Sci 57 (2012), p. 1010-1060.

[4] S. Hinotani, Y Ohmori, J Jpn Inst Metals 29 (1988), p. 116-124.

[5] P. Vyskocil, et al, Acta Mater 45 (1997), p. 3311-3318.
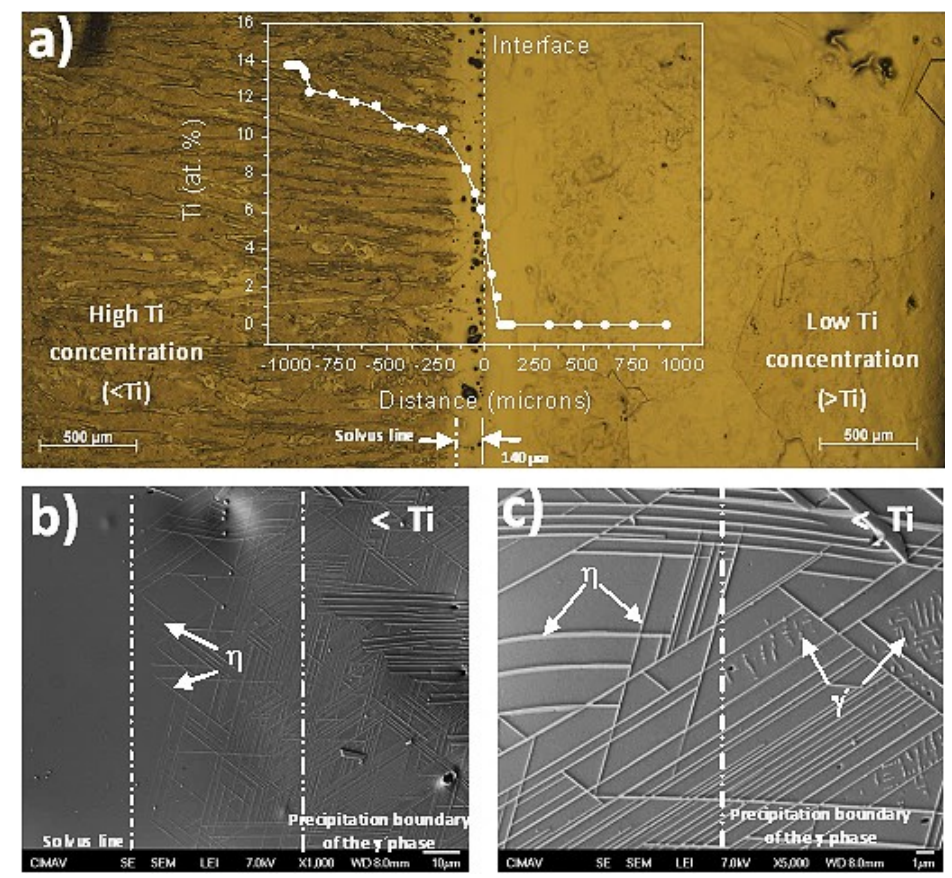

Figure 1. a) Optical micrograph of $\mathrm{Ni}-13.75 \mathrm{Ti}$ (at. \%)/Ni diffusion couple and $\mathrm{Ti}$ concentration profile, b) and c) FE-SEM images indicating the solvus line (---) and precipitation boundary of the $\gamma^{\prime}$ phase ($\left.\cdots_{-} \cdot-_{-}\right)$.
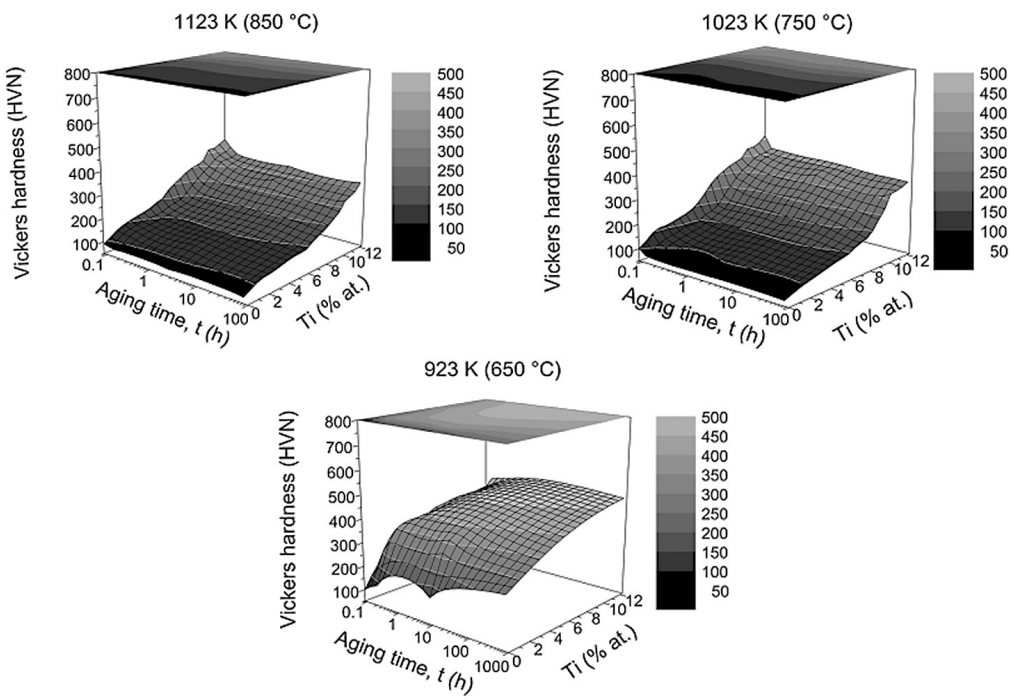

Figure 2. Age-hardening curves obtained as a function of Ti concentration at 850,750 and $650{ }^{\circ} \mathrm{C}$. 